\title{
Comparison of Short-term Surgical Outcomes between a Robotic Colectomy and a Laparoscopic Colectomy during
} Early Experience

\author{
Jin Yong Shin \\ Department of Surgery, Inje University Haeundae Paik Hospital, Inje University College of Medicine, Busan, Korea
}

Purpose: Although robotic surgery was invented to overcome the technical limitations of laparoscopic surgery, the role of a robotic (procto)colectomy (RC) for the treatment of colorectal cancer compared to that of a laparoscopic (procto)colectomy (LC) was not well defined during the initial adoption periods of both procedures. This study aimed to evaluate the efficacy and the safety of a RC for the treatment of colorectal cancer by comparing the authors' initial experiences with both a RC and a LC.

Methods: The first 30 patients treated by using a RC for colorectal cancer from July 2010 to March 2011 were compared with the first 30 patients treated by using a LC for colorectal cancer from December 2006 to June 2007 by the same surgeon. Perioperative variables and short-term outcomes were analyzed. In addition, the $30 \mathrm{RC}$ and the $30 \mathrm{LC}$ cases involved were divided into rectal cancer $(n=17$ and $n=12$, respectively), left-sided colon cancer ( $n=7$ and $n=12$, respectively) and right-sided colon cancer ( $\mathrm{n}=6$ and $\mathrm{n}=6$, respectively) for subgroup analyses.

Results: The mean operating times for RC and LC were significantly different at 371.8 and 275.5 minutes, respectively, but other perioperative parameters (rates of open conversion, numbers of retrieved lymph node, estimated blood losses, times to first flatus, maximal pain scores before discharge and postoperative hospital stays) were not significantly different in the two groups. Subgroup analyses showed that the mean operative times for a robotic proctectomy and a laparoscopic proctectomy were 396.5 and 298.8 minutes, respectively $(\mathrm{P}<0.000)$. Postoperative complications occurred in five patients in the $\mathrm{RC}$ group and in six patients in the LC group $(\mathrm{P}=0.739)$.

Conclusion: Although the short-term outcomes of a RC during its initial use were better than those of a LC (with the exception of operating time), differences were not found to be significantly different. On the other hand, the longer operation time of a robotic proctectomy compared to that of a laparoscopic proctectomy during the early period may be problematic.

Keywords: Robotics; Laparoscopic surgery; Patients outcomes

\section{INTRODUCTION}

Laparoscopic colorectal surgery for cancer has gained in popularity in recent years, and according to multicenter studies, this has

Received: October 9, 2011 Revised: November 14, 2011

Accepted: December 20, 2011

Correspondence to: Jin Yong Shin, M.D.

Department of Surgery, Inje University Haeundae Paik Hospital, Inje University College of Medicine, 875 Haeun-daero, Haeundae-gu, Busan 612-862, Korea Tel: +82-51-742-7725, Fax: +82-51-797-0261

E-mail: jyong@medigate.net

(C) 2012 The Korean Society of Coloproctology

This is an open-access article distributed under the terms of the Creative Commons Attribution NonCommercial License (http://creativecommons.org/licenses/by-nc/3.0) which permits unrestricted noncommercial use, distribution, and reproduction in any medium, provided the original work is properly cited. result in long-term oncologic outcomes comparable to those of open surgery, shorter hospital stays and less postoperative pain [1-3] However, two-dimensional imaging, limited dexterity and a long learning curve [4] are considered limitations of laparoscopic colorectal surgery.

The robotic (procto)colectomy (RC) was first reported in 2001 [5]. This technique was developed to compensate for the technical limitations of the laparoscopic (procto)colectomy (LC) and provides three-dimensional imaging, excellent ergonomics as compared with those of conventional laparoscopic instrumentation, camera operation by the surgeon, and stable traction of the operative field. For these reasons, the role of the $\mathrm{RC}$ has been expanding as a form of minimally invasive surgery for the treatment of colorectal disorders [6]. Furthermore, several authors have commented 
on the adaptability of robotic surgery $[7,8]$, which suggests that the learning curve of robotic surgery is shorter than that of laparoscopic surgery. However, despite these advantages, a few issues related to the RC must be considered, such as the longer operative times $[9,10]$ and large operative fields [11]. Furthermore, its incorporation into clinical practice has been comparatively slow [6]. The aim of this study was to evaluate the role of the RC as a tool for minimally invasive surgery for colorectal cancer by comparing the short-term outcomes of the RC and the LC during their early adoption periods.

\section{METHODS}

The prospectively collected data of first 30 consecutive patients that underwent a RC for colorectal cancer from July 2010 to March 2011 at Inje University Haeundae Paik Hospital and of the first 30 consecutive patients that underwent a LC for colorectal cancer from December 2006 to June 2007 at Inje University Busan Paik Hospital by one surgeon were reviewed retrospectively. The clinical parameters analyzed included patients characteristics and perioperative outcomes (operative times, intraoperative blood losses, conversion rate to open surgery, numbers of lymph nodes retrieved, day of first flatus passage, maximal visual analogue scale pain score before discharge, and postoperative length of hospital stay). Tumors were classified as follows: 1) rectal cancer was defined as a tumor located below $15 \mathrm{~cm}$ from the anal verge as measured preoperatively by using rigid sigmoidoscopy; 2) right-sided colon cancer was defined as a tumor located between the cecum and the transverse colon; 3) left-sided colon cancer was defined as a tumor located between the splenic flexure and the sigmoid colon. Operative time was calculated as the time between the first incision and wound closure, and intraoperative blood loss was measured by subtracting instilled fluid volume from aspirated volume. Patients were staged using the tumor node metastasis (TNM) 7th edition, and patients with $\mathrm{T} 4$ cancer at preoperative staging were excluded from minimally invasive surgery. The da Vinci SH (Intuitive Surgical Inc., Sunnyvale, CA, USA) was used for the RC in all cases.

\section{Operative technique}

Robotic left-sided colectomy including proctectomy

Pneumoperitoneum was established using an open method through a right paraumbilical incision, and a $12-\mathrm{mm}$ optical trocar for the camera was inserted. After careful exploration of the intraabdominal cavity for detection of metastasis, four 8-mm trocars were placed under direct vision, one each in the right lower quadrant, the right upper quadrant from $5-\mathrm{cm}$ xyphoid process on the right side of the falciform ligament, the right suprapubic area, and the left lower quadrant on the lateral margin of the rectus muscle. A 5 - $\mathrm{mm}$ trocar for the assistant at the operating table was inserted in the right mid-abdomen at the level of the umbilicus.

The hybrid technique for the robotic proctectomy was performed as follows: Ligation of the inferior mesenteric vein and mobilization of the left sided colon were carried out laparoscopically. Thereafter, division of the inferior mesenteric artery and rectal mobilization were performed robotically. The totally robotic procedure for the robotic proctectomy consisted of a colonic phase and a rectal phase, and dual docking was necessary to complete both parts of the procedure. During the colonic phase, the patients were positioned in the lithotomy position with slight Trendelenberg positioning with right lateral tilt. The first robotic arm was placed at the right lower port, and the second and third arms were placed at the right upper and right suprapubic ports, respectively. A monopolar scissor was used in the first robotic arm, a bipolar forcep in the second robotic arm, and a double fenestrated grasper in the third robotic arm (Fig. 1). Initially, the inferior mesenteric artery (IMA) was retracted with the double fenestrated forceps, and the IMA was ligated near the origin by using robotic clip placement. Thereafter, division of the inferior mesenteric vein with a robotic clip was performed close to the Treitz ligament. The medial-to-lateral dissection was continued until the left-sided colon was sepa-
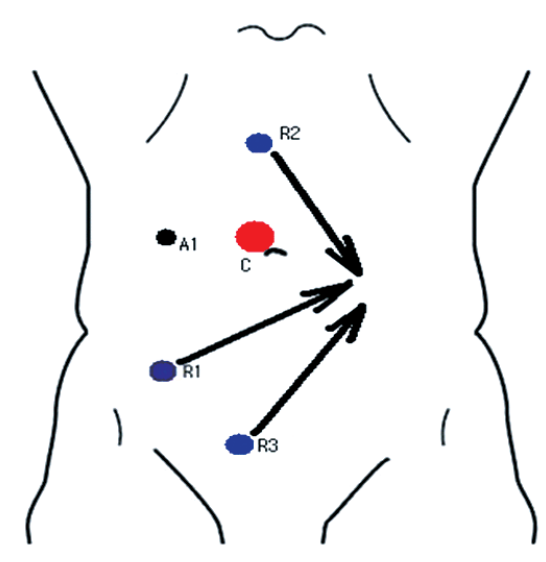

(A)

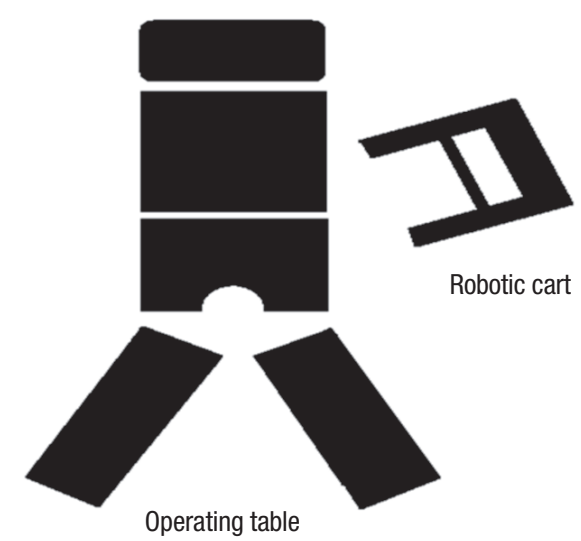

Fig. 1. (A) Port placement and (B) positioning of robotic system for a robotic proctectomy during the colic phase. A represents the assistant port. 
rated from the retroperitoneum; the left ureter and gonadal vessels were then identified and preserved. During splenic mobilization, the double fenestrated forcep in the third robotic arm was used to retract the left-sided colon to the right side of the patients, and the splenic flexure was freed from the omentum and surrounding tissues. After the colonic phase had been completed, robotic arms were detached, and the da Vinci system was docked by coming in over the patient's left hip at an angle of about $30^{\circ}$ in relation to the operating table. The third robotic arm in the suprapubic port was then moved to the left lower quadrant port (Fig. 2). Rectal mobilization was initiated by dissecting the pelvic cavity along the avascular plane between the fascia propria of the rectum and the parietal fascia, and a total mesorectal excision or a partial mesorectal excision was then performed, depending on the tumor's location. After of the rectal mobilization had been completed, the rectum was divided using a linear stapling device through the right lower quadrant port or the suprapubic port. The specimen was then extracted through the right lower quadrant, or suprapubic minilapa- rotomy and anastomosis were created.

\section{Robotic right-sided colon resection}

After establishment of pneumoperitoneum by using a veres needle, a 12-mm optical trocar for the camera was inserted to the left of the umbilicus. Three 8-mm trocars were placed, one each, in the left upper quadrant, the suprapubic area, and the right lower quadrant, and a 5-mm trocar for the assistant was inserted in the left mid-abdomen. The patient was maintained in a mild Trendelenburg position with left lateral tilt in order to help remove the small bowel from the operative field. The three working arms carried a monopolar scissor in the left upper quadrant port, a bipolar forcep in the suprapubic port and a double fenestrated forcep in the right lower quadrant (Fig. 3).

The procedure was started by applying traction to the mesentery of the terminal ileum with the third robotic arm. Mobilization of the colon was carried out inferior to the superior direction in the avascular plane between Gerota's fascia and Toldt's fascia. During

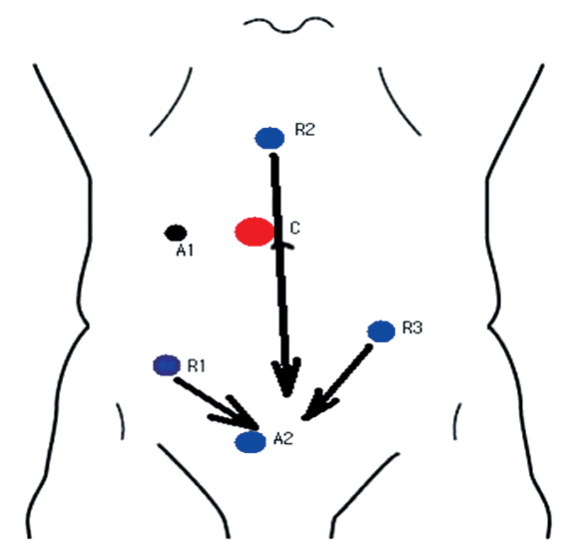

(A)

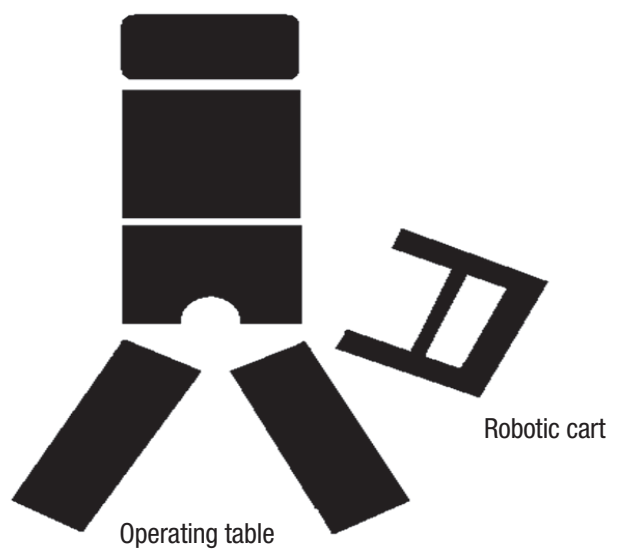

(B)

Fig. 2. (A) Port placement and (B) positioning of robotic system for a robotic proctectomy during the pelvic phase. A represents the assistant port.
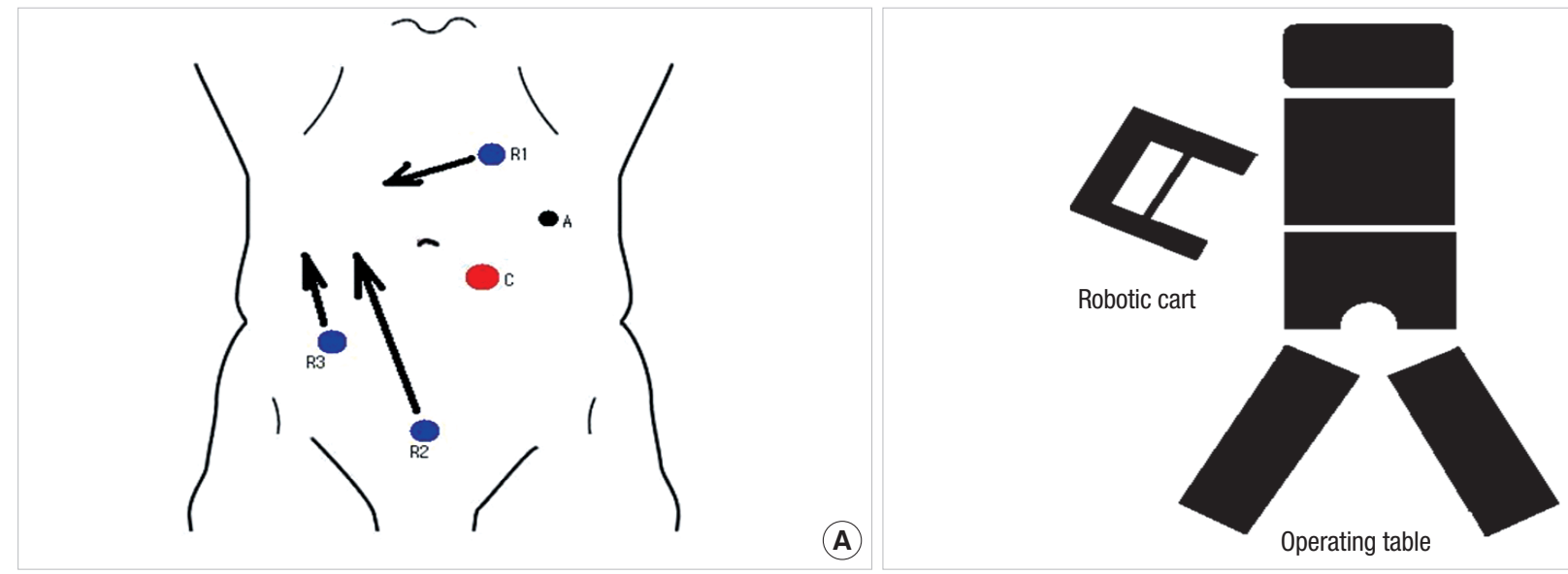

Fig. 3. (A) Port placement and (B) positioning of robotic system for a robotic right hemicolectomy. A represents the assistant port. 
this procedure, the duodenum was used as a landmark for safe upward dissection. The ileocolic vessel was then isolated and separately ligated near the superior mesenteric vessel with robotic clips (Hemolok). Thereafter, using a dissection along the lateral part of the middle colic vessel, the middle colic vessel was severed based on the tumor's location. The gastrocolic trunk from the superior mesenteric vein was then exposed, and its branch or branches were ligated with a robotic clip or clips. The greater omentum was then divided and dissected toward the hepatic flexure. The suprapubic port was enlarged to approximately $5 \mathrm{~cm}$ for specimen retrieval, and an ileocolic anastomosis was completed extracorporeally.

\section{Laparoscopic surgery}

The laparoscopic procedure used was similar to that described above for robotic surgery. A camera port was inserted through a vertical incision just below the umbilicus by using the open method, and the other four trocars were used in the right and the left lower quadrants, the right mid-abdomen and the left upper quadrant.

\section{Statistical analysis}

Stastistical analyses were performed using the SPSS ver. 12.0 (SPSS Inc., Chicago, IL, USA). Intergroup differences in parametric and nonparametric variables were compared using the t-test or the Mann-Whitney U test as appropriate. The chi-square or the Fisher's exact test for categorical variables was used to test for the significances of differences between groups. P-values $<0.05$ were considered statistically significant.

\section{RESULTS}

\section{Preoperative characteristics of patients}

The preoperative clinical characteristics of patients in the RC and the LC groups are presented in Table 1. Sex ratios, overweight proportions (body mass index > 25), American Society of Anesthesiologists Score $>2$ proportions, TNM stage distributions and previous histories of abdominal surgery were similar in the two groups. However, the mean age in the RC group was significantly lower (58.1 years vs. 63.3 years; $\mathrm{P}=0.042$ ) (Table 1 ).

\section{Perioperative short-term outcomes in the RC and the LC groups}

Table 2 presents perioperative short-term outcomes after surgery. The low anterior resection $(n=9)$ and the ultralow anterior resection $(n=7)$ were the most common procedures in the RC group whereas the high anterior resection $(n=13)$ and the low anterior resection $(n=12)$ were most common in the LC group. However, the distribution of operative procedures performed was similar in the two groups ( $P=0.169)$. The mean operative time was significantly longer in the RC group (371.8 minutes vs. 275.5 minutes; $\mathrm{P}<0.000$ ). The mean robotic surgical time (console time), defined as time from first operation of the robotic instruments by the surgeon at the console to the release of the masters at the end of the
Table 1. Characteristics of the patients who underwent robotic or laparoscopic colectomies

\begin{tabular}{|c|c|c|c|}
\hline Characteristic & $\begin{array}{l}\text { Robotic } \\
\text { colectomy } \\
(\mathrm{n}=30)\end{array}$ & $\begin{array}{l}\text { Laparoscopic } \\
\text { colectomy } \\
(n=30)\end{array}$ & P-value \\
\hline Age (yr) & $58.1 \pm 8.6$ & $63.3 \pm 7.9$ & $0.042^{\mathrm{a}}$ \\
\hline Sex & & & $1.000^{\mathrm{b}}$ \\
\hline Male & 18 & 18 & \\
\hline Female & 12 & 12 & \\
\hline $\mathrm{BMI}\left(\mathrm{kg} / \mathrm{m}^{2}\right)$ & & & $0.779^{b}$ \\
\hline$>25$ & 22 & 20 & \\
\hline$\leq 25$ & 8 & 10 & \\
\hline ASA & & & $0.246^{b}$ \\
\hline ।, II & 30 & 28 & \\
\hline III & 0 & 2 & \\
\hline Previous abdominal surgery & 1 & 3 & $0.306^{\mathrm{b}}$ \\
\hline Tumor location & & & $0.337^{b}$ \\
\hline Rectum & 17 & 12 & \\
\hline Left-sided colon & 7 & 12 & \\
\hline Right-sided colon & 6 & 6 & \\
\hline TNM stage & & & $0.331^{\mathrm{b}}$ \\
\hline I & 6 & 10 & \\
\hline$\|$ & 7 & 5 & \\
\hline III & 15 & 14 & \\
\hline IV & 2 & 1 & \\
\hline
\end{tabular}

Values are presented as mean $\pm S D$ or number.

BMI, body mass index; ASA, American Society of Anesthesiologists.

${ }^{a}$ The P-value is calculated from the independent t-test; ${ }^{\mathrm{b}}$ The P-value is calculated from the chi-squared test or Fisher's exact test.

procedure, was 191.2 minutes, and the mean docking time of the robot, defined as time from initiating robotic approach to the operative table and connecting the robotic arms to the ports, was 11.9 minutes. Conversion to open surgery was required in three patients in the LC group due to intraoperative hemorrhage ( $\mathrm{P}=$ 0.119). A diverting stoma was constructed when the anastomosis was problematic as determined by the surgeon, when the air-leak test was positive, or when the bowel preparation was poor. A loop ileostomy was created in six of seven patients that underwent an ultralow anterior resection and in three of nine patients that underwent a low anterior resection in the RC group. One patient in the LC group, who underwent a high anterior resection had a protecting ileostomy constructed due to poor bowel preparation. Although no statistically significant differences were found, the amount of blood loss was smaller and the number of lymph node retrieved was greater in the RC group. Furthermore, no significant differences were found for postoperative pain scores or for postoperative hospital stays (Table 2). 
Table 2. Perioperative parameters according to operative methods

\begin{tabular}{|c|c|c|c|}
\hline Parameter & $\begin{array}{l}\text { Robotic } \\
\text { colectomy } \\
(\mathrm{n}=30)\end{array}$ & $\begin{array}{l}\text { Laparoscopic } \\
\text { colectomy } \\
(n=30)\end{array}$ & P-value \\
\hline Procedure & & & $0.169^{a}$ \\
\hline uLAR & $7(6)$ & 0 & \\
\hline LAR & $9(3)$ & 12 & \\
\hline HAR & 8 & $13(1)$ & \\
\hline $\mathrm{RHC}$ & 6 & 5 & \\
\hline \multicolumn{4}{|l|}{ Operative approach } \\
\hline Totally robotic & 21 & NA & \\
\hline Hybrid & 9 & NA & \\
\hline Operative time (min) & $371.8 \pm 87.5$ & $275.5 \pm 54.1$ & $<0.000^{\mathrm{b}}$ \\
\hline Console time (min) & $191.2 \pm 48.7$ & NA & \\
\hline Docking time (min) & $11.9 \pm 4.4$ & NA & \\
\hline Open conversion & 0 & 3 & $0.119^{a}$ \\
\hline Estimated blood loss (mL) & $167.3 \pm 119.7$ & $205.5 \pm 147.8$ & $0.320^{b}$ \\
\hline Retrieved LN & $18.4 \pm 10.1$ & $15.9 \pm 5.9$ & $0.233^{b}$ \\
\hline First flatus passage (day) & $3.2 \pm 0.8$ & $3.5 \pm 1.1$ & $0.195^{b}$ \\
\hline Postoperative hospital stay (day) & $10.3 \pm 2.8$ & $9.2 \pm 2.0$ & $0.080^{b}$ \\
\hline Maximal pain score (VAS) & $5.7 \pm 2.1$ & $5.9 \pm 1.7$ & $0.686^{b}$ \\
\hline
\end{tabular}

Values are presented as number (patients with protective stoma), number or mean \pm SD.

ULAR, ultralow anterior resection; LAR, low anterior resection; HAR, high anterior resection; $\mathrm{RHC}$, right hemicolectomy; NA, not applicable; LN, lymph node; VAS, visual analogue scale.

${ }^{a}$ The P-value is calculated from the chi-squared test or Fisher's exact test; ${ }^{\text {bThe }}$ $P$-value is calculated from the independent t-test.

\section{Perioperative short-term outcomes according to tumor location}

No significant differences were found between the RC and the LC groups in terms of general characteristics (data not shown). In the robotic proctectomy subgroup, the mean docking and the console times were 13.1 minutes and 203.2 minutes, respectively. The mean operative time was 396.5 minutes in the robotic proctectomy subgroup and 298.8 minutes in the laparoscopic proctectomy subgroup $(\mathrm{P}<0.000)$. With respect to tumor location from the anal verge, the mean distance from the anal verge was $8.1 \mathrm{~cm}$ in the robotic proctectomy subgroup and $10.5 \mathrm{~cm}$ in the laparoscopic proctectomy subgroup $(\mathrm{P}=0.016)$. Furthermore, perioperative shortterm parameters were more favorable in the robotic proctectomy subgroup with respect to blood loss, numbers of retrieved lymph nodes, postoperative pain score and time to first flatus. However, postoperative hospital stay was shorter in the laparoscopic proctectomy subgroup. However, no statistical differences were noted in comparisons of all the above-mentioned parameters.

Conversion to open surgery was only necessary in one patient in the laparoscopic proctectomy subgroup, and there was no significant difference in the conversion rate of open surgery between the two groups (Table 3). Comparison of perioperative short-term outcomes for left-sided colectomy cases and right-sided colectomy cases in the RC and the LC subgroups showed that the mean operative times for robotic left-sided and right-sided surgery were 337.1 minutes and 342.5 minutes, respectively, and that those for laparoscopic left-sided and right-sided surgery were 264.8 minutes and 250.8 minutes, respectively, which constituted a trend toward longer operative time in the robotic surgery subgroup $(\mathrm{P}=0.060$, $\mathrm{P}=0.054)$. Subgroup comparisons of other parameters such as

Table 3. Comparison of perioperative parameters

\begin{tabular}{|c|c|c|c|c|c|c|c|c|c|}
\hline \multirow[b]{2}{*}{ Parameter } & \multicolumn{3}{|c|}{ Patients with rectal cancer } & \multicolumn{3}{|c|}{ Left-sided colon cancer } & \multicolumn{3}{|c|}{ Right-sided colon cancer } \\
\hline & $\begin{array}{l}\text { Robotic } \\
\text { proctectomy }^{a} \\
(\mathrm{n}=17)\end{array}$ & $\begin{array}{l}\text { Laparoscopic } \\
\text { proctectomy } \\
(n=12)\end{array}$ & $\begin{array}{c}\mathrm{P} \text { - } \\
\text { value }\end{array}$ & $\begin{array}{l}\text { Roboitic } \\
\text { colectomy }^{a} \\
(\mathrm{n}=7)\end{array}$ & $\begin{array}{l}\text { Laparoscopic } \\
\text { colectomy } \\
(n=12)\end{array}$ & $\begin{array}{c}\text { P- } \\
\text { value }\end{array}$ & $\begin{array}{l}\text { Roboitic } \\
\text { colectomy }^{\mathrm{a}} \\
(\mathrm{n}=6)\end{array}$ & $\begin{array}{l}\text { Laparoscopic } \\
\text { colectomy } \\
(n=6)\end{array}$ & $\begin{array}{c}\mathrm{P}- \\
\text { value }\end{array}$ \\
\hline Operative time (min) & $396.5 \pm 41.7$ & $298.8 \pm 36.6$ & $<0.000^{\mathrm{b}}$ & $337.1 \pm 137.5$ & $264.8 \pm 70.7$ & $0.06^{b}$ & $342.5 \pm 106.5$ & $250.8 \pm 26.3$ & $0.054^{b}$ \\
\hline Console time (min) & $203.2 \pm 31.7$ & NA & & $139.3 \pm 25.7$ & NA & & $217.5 \pm 68.2$ & NA & \\
\hline Docking time (min) & $13.1 \pm 4.5$ & NA & & $8.3 \pm 2.1$ & NA & & $12.7 \pm 4.2$ & NA & \\
\hline Open conversion & 0 & 1 & $0.414^{c}$ & 0 & 0 & $1.000^{c}$ & 0 & 2 & $0.227^{\circ}$ \\
\hline Estimated blood loss (mL) & $188.8 \pm 70.4$ & $229.2 \pm 130.5$ & $0.276^{b}$ & $105.7 \pm 80.0$ & $166.7 \pm 61.5$ & $0.131^{\mathrm{b}}$ & $185.0 \pm 70.4$ & $241.7 \pm 188.2$ & $0.871^{\mathrm{b}}$ \\
\hline Retrieved LN & $16.5 \pm 7.5$ & $14.1 \pm 6.1$ & $0.564^{b}$ & $16.9 \pm 6.6$ & $16.2 \pm 4.7$ & $0.899^{b}$ & $25.8 \pm 16.4$ & $18.8 \pm 6.8$ & $0.936^{\mathrm{b}}$ \\
\hline First flatus passage (day) & $3.0 \pm 1.0$ & $3.4 \pm 1.1$ & $0.326^{b}$ & $3.3 \pm 0.7$ & $3.6 \pm 1.1$ & $0.608^{b}$ & $3.5 \pm 0.5$ & $3.6 \pm 2.1$ & $0.784^{b}$ \\
\hline Postoperative hospital stay (day) & $10.7 \pm 3.3$ & $9.6 \pm 2.3$ & $0.420^{b}$ & $9.1 \pm 1.7$ & $8.9 \pm 2.1$ & $0.622^{b}$ & $10.7 \pm 2.1$ & $8.8 \pm 1.5$ & $0.123^{\mathrm{t}}$ \\
\hline Maximal pain score (VAS) & $5.8 \pm 2.1$ & $6.1 \pm 1.6$ & $0.787^{\mathrm{b}}$ & $5.3 \pm 2.2$ & $5.3 \pm 1.8$ & $0.898^{\mathrm{b}}$ & $5.8 \pm 2.3$ & $6.5 \pm 1.5$ & $0.682^{b}$ \\
\hline Tumor distance from AV (cm) & $8.1 \pm 3.8$ & $10.5 \pm 1.7$ & $0.016^{b}$ & & & & & & \\
\hline
\end{tabular}

Values are presented as mean \pm SD or number.

NA, not applicable; LN, lymph node; VAS, visual analogue scale.

The baseline characteristics (age, gender ratio, body mass index, history of previous abdominal operation, distribution of operative procedures and tumor stage) of robotic groups were similar to those of laparoscopic groups; ${ }^{\mathrm{b} T}$ The P-value is calculated from the Mann Whitney U test; ' ${ }^{\mathrm{C}}$ The P-value is calculated from Fisher's exact test. 
Table 4. Postoperative complication and management according to operative method

\begin{tabular}{lcccc}
\hline Variable & $\begin{array}{c}\text { Robotic } \\
\text { proctectomy } \\
(\mathrm{n}=30)\end{array}$ & $\begin{array}{c}\text { Laparoscopic } \\
\text { proctectomy } \\
(\mathrm{n}=30)\end{array}$ & $\begin{array}{c}\text { P- } \\
\text { value }\end{array}$ & Management \\
\hline SB0 & 2 & 3 & $\begin{array}{c}\text { Conservative } \\
\text { management }\end{array}$ \\
Chylous ascites & 1 & 0 & $\begin{array}{c}\text { Conservative } \\
\text { management }\end{array}$ \\
Urinary dysfunction & 1 & 2 & $\begin{array}{c}\text { Spontaneously } \\
\text { recovered }\end{array}$ \\
Parastomal hernia & 1 & 0 & & $\begin{array}{c}\text { Observation } \\
\text { Pelvic abscess }\end{array}$ \\
Total & 0 & 1 & $0.739^{\mathrm{a}}$ & \\
\hline
\end{tabular}

SBO, small bowel obstruction; NS, not significant.

${ }^{\text {a }}$ The P-value is calculated from the chi-squared test.

amount of blood loss, number of retrieved lymph nodes, time to first flatus, postoperative pain score and postoperative hospital stay, revealed no statistical differences (Table 3).

\section{Postoperative morbidity}

In the RC group, five patients experienced postoperative complications, including early postoperative small bowel obstruction, ileostomy stenosis and chylous leakage. Early small-bowel obstruction, which occurred on postoperative day 8 , was managed conservatively. One patient with ileostomy stenosis on postoperative day 10 was successfully treated by reversal of the ileostomy at 4 weeks postoperatively. The one patient with postoperative chylous leakage responded to a low fat diet for 7 days. Six postoperative complications occurred in the LC group. Early postoperative smallbowel obstruction occurred in 3 patients (on postoperative days 5 , 7 and 14) and all recovered on conservative therapy. The one patient that developed a pelvic abscess was managed by drainage of the pelvic collection. The overall group complication rates were not significantly different (Table 4).

\section{DISCUSSION}

Since the first report was issued on the use of a robot-assisted colectomy for a benign disorder in 2001 [5], several comparative studies [12-15] of perioperative short-term outcomes of RC and LC have described the feasibility and the safety of robotic surgery for the management of benign and malignant colorectal diseases. However, opinions differ regarding the learning curve of robotic surgery for colorectal disorders. Hellan et al. [16] described the learning curve of robotic rectal surgery as faster than that for laparoscopic rectal surgery. However, there was a suggestion that difficulties associated with accessing multiple abdominal quadrants during robotic colorectal surgery might lead to the development of hybrid procedures for a RC [11]. The observation in the pres- ent study that the operative time was greater in the RC group supports the opinion that a RC is not easily learned [11]. However, when the patients enrolled in this study were subdivided into rectal surgery, left-sided colonic surgery and right-sided colonic surgery groups, only the operative time for the rectal surgery subgroup was significantly different in a comparison of the operative times between the RC and the LC subgroups (mean, 396.5 minutes vs. 298.8 minutes). This result differs from that of previous studies which found no difference between the operative times for robotic and laparoscopic proctectomies [12, 14]. The reason for the longer operative time for the robotic proctectomy group appears to be related to less experience of the surgeon and the surgical team. As Spinoglio et al. [9] and D'Annibale et al. [17] suggested in their reports, operation times will be reduced with increasing surgeon experience.

In this study, the mean console time was 203.2 minutes for the 17 patients that underwent a robotic proctectomy, 139.3 minutes for the 7 patients that underwent a robotic left colectomy and 217.5 minutes for the 6 patients that underwent a robotic right colectomy. Previous studies [17-20] have reported mean console times for robotic proctectomies [18, 19], sigmoid colectomies [20] and right colectomies of 180,100 , and 180 minutes, respectively $[17,20]$. Although the console time found in the current study was somewhat longer than those reported in previous publications [17-20], only small numbers of patients were included in those previous articles.

The mean docking time of 11.9 minutes found in this study (range, 5 to 15 minutes) agrees with previous studies $[18,21,22]$ and was greater in the proctectomy subgroup (13.1 minutes), which is presumed to be due to the requirement for intraoperative re-docking. In addition, the relatively long docking time of 12.7 minutes found for the robotic right colectomy seems to be related to the fact that five of the six patients underwent the procedure soon after the first use of robotic surgery.

With regard to tumor location, the rectum was the most common location (56.7\%) in the RC group. The mean tumor distance from the anal verge was significantly shorter in the $\mathrm{RC}$ group than in the LC group $(8.1 \mathrm{~cm}$ vs. $10.5 \mathrm{~cm}$ ) when the comparison was limited to the patients with rectal cancer. This result indicates that it is possible to apply robotic surgery to relatively low rectal lesions even during the initial learning period and seems to be in agreement with the suggestion made in a previous paper [23], in which the advantages of robotic surgery in patients with a deep and confined surgical field, such as the pelvis, were described. However, given that the surgeon involved in the present study was an experienced laparoscopic colorectal surgeon at the beginning of robotic surgery, it is not conclusive whether the robotic proctectomy has advantages over the laparoscopic proctectomy in terms of ease of deep pelvic dissection in rectal surgery during the early learning period.

The hybrid technique using exclusively robotics for rectal dissection in performing a robotic proctectomy $[10,14,22]$ has many 
potential advantages, such as fewer ports and shorter operative times [10, 22]. After a hybrid technique with laparoscopic colonic mobilization and robotic pelvic dissection had been performed in the first nine patients, I switched to a totally robotic technique for the remaining eight patients. However, because the mean operative time was longer for the hybrid technique than for the totally robotic technique (409.4 minutes vs. 396.5 minutes), no operative time advantage was found for the hybrid technique. Furthermore, given that the hybrid technique for the robotic proctectomy was performed during the early period and that a few studies have described a totally robotic proctectomy to maximize the merits of robotic surgery $[18,20]$, further study is required to evaluate the technical advantages of the totally robotic approach to a robotic proctectomy.

The high rate of conversion to open surgery reported in a multicenter trial [2] raised concerns regarding the feasibility of laparoscopic colorectal surgery. The present study shows that conversion to open surgery was required to complete the procedure in $10 \%$ of patients that underwent a LC. However, no patient in the RC group was converted to open laparotomy, and this is consistent with previous publications that reported a lower conversion rate of less than five percent for the robotic approach $[9,10,12-16]$. The zero conversion rate for the $\mathrm{RC}$ group is presumed to be due to the surgeon's experience, with more than 400 cases of colorectal surgery using the laparoscopic approach. In view of the negative impact of conversion on perioperative outcomes, the result obtained in the present study indicates that conversion to open surgery may be lower for the $\mathrm{RC}$ than for the LC, even during the early period.

In this study, blood loss, numbers of retrieved lymph node, times to first flatus and postoperative pain were similar in the RC and the LC groups, and these finding concur with previous reports [9, $10,12-16]$. However, although not significant, the amount of blood loss was less and the number of retrieved lymph node was larger in the $\mathrm{RC}$ group. These observations require further examination by prospective multicenter studies comparing the short-term outcomes of the RC and the LC.

In conclusion, the short-term outcomes of a $\mathrm{RC}$ were found to be marginally better than those of a LC (with the exception of operating time) during the early learning period. However, the longer operation time of robotic proctectomy as compared with a laparoscopic proctectomy during the early period may be problematic.

\section{CONFLICT OF INTEREST}

No potential conflict of interest relevant to this article was reported.

\section{REFERENCES}

1. Clinical Outcomes of Surgical Therapy Study Group. A comparison of laparoscopically assisted and open colectomy for colon cancer. N Engl J Med 2004;350:2050-9.

2. Jayne DG, Guillou PJ, Thorpe H, Quirke P, Copeland J, Smith AM, et al. Randomized trial of laparoscopic-assisted resection of colorectal carcinoma: 3-year results of the UK MRC CLASICC Trial Group. J Clin Oncol 2007;25:3061-8.

3. Lacy AM, García-Valdecasas JC, Delgado S, Castells A, Taurá P, Piqué JM, et al. Laparoscopy-assisted colectomy versus open colectomy for treatment of non-metastatic colon cancer: a randomised trial. Lancet 2002;359:2224-9.

4. D’Annibale A, Morpurgo E, Fiscon V, Trevisan P, Sovernigo G, Orsini $\mathrm{C}$, et al. Robotic and laparoscopic surgery for treatment of colorectal diseases. Dis Colon Rectum 2004;47:2162-8.

5. Weber PA, Merola S, Wasielewski A, Ballantyne GH. Teleroboticassisted laparoscopic right and sigmoid colectomies for benign disease. Dis Colon Rectum 2002;45:1689-94.

6. Mirnezami AH, Mirnezami R, Venkatasubramaniam AK, Chandrakumaran K, Cecil TD, Moran BJ. Robotic colorectal surgery: hype or new hope? A systematic review of robotics in colorectal surgery. Colorectal Dis 2010;12:1084-93.

7. Corcione F, Esposito C, Cuccurullo D, Settembre A, Miranda N, Amato F, et al. Advantages and limits of robot-assisted laparoscopic surgery: preliminary experience. Surg Endosc 2005;19:117-9.

8. Rashid TG, Kini M, Ind TE. Comparing the learning curve for robotically assisted and straight stick laparoscopic procedures in surgical novices. Int J Med Robot 2010;6:306-10.

9. Spinoglio G, Summa M, Priora F, Quarati R, Testa S. Robotic colorectal surgery: first 50 cases experience. Dis Colon Rectum 2008;51:1627-32.

10. Park JS, Choi GS, Lim KH, Jang YS, Jun SH. Robotic-assisted versus laparoscopic surgery for low rectal cancer: case-matched analysis of short-term outcomes. Ann Surg Oncol 2010;17:3195-202.

11. Giulianotti PC, Coratti A, Angelini M, Sbrana F, Cecconi S, Balestracci T, et al. Robotics in general surgery: personal experience in a large community hospital. Arch Surg 2003;138:777-84.

12. Bianchi PP, Ceriani C, Locatelli A, Spinoglio G, Zampino MG, Sonzogni A, et al. Robotic versus laparoscopic total mesorectal excision for rectal cancer: a comparative analysis of oncological safety and short-term outcomes. Surg Endosc 2010;24:2888-94.

13. Patriti A, Ceccarelli G, Bartoli A, Spaziani A, Biancafarina A, Casciola L. Short- and medium-term outcome of robot-assisted and traditional laparoscopic rectal resection. JSLS 2009;13:176-83.

14. Baik SH, Ko YT, Kang CM, Lee WJ, Kim NK, Sohn SK, et al. Robotic tumor-specific mesorectal excision of rectal cancer: shortterm outcome of a pilot randomized trial. Surg Endosc 2008;22: 1601-8.

15. Rawlings AL, Woodland JH, Vegunta RK, Crawford DL. Robotic versus laparoscopic colectomy. Surg Endosc 2007;21:1701-8.

16. Hellan M, Anderson C, Ellenhorn JD, Paz B, Pigazzi A. Short-term outcomes after robotic-assisted total mesorectal excision for rectal cancer. Ann Surg Oncol 2007;14:3168-73.

17. D’Annibale A, Pernazza G, Morpurgo E, Monsellato I, Pende V, Lucandri $\mathrm{G}$, et al. Robotic right colon resection: evaluation of first 50 consecutive cases for malignant disease. Ann Surg Oncol 2010; 17:2856-62. 
18. Park YA, Kim JM, Kim SA, Min BS, Kim NK, Sohn SK, et al. Totally robotic surgery for rectal cancer: from splenic flexure to pelvic floor in one setup. Surg Endosc 2010;24:715-20.

19. Obias V, Sanchez C, Nam A, Montenegro G, Makhoul R. Totally robotic single-position 'flip' arm technique for splenic flexure mobilizations and low anterior resections. Int J Med Robot 2011; 7:123-6.

20. Rawlings AL, Woodland JH, Crawford DL. Telerobotic surgery for right and sigmoid colectomies: 30 consecutive cases. Surg En- dosc 2006;20:1713-8.

21. Bokhari MB, Patel CB, Ramos-Valadez DI, Ragupathi M, Haas EM. Learning curve for robotic-assisted laparoscopic colorectal surgery. Surg Endosc 2011;25:855-60.

22. deSouza AL, Prasad LM, Marecik SJ, Blumetti J, Park JJ, Zimmern A, et al. Total mesorectal excision for rectal cancer: the potential advantage of robotic assistance. Dis Colon Rectum 2010;53:1611-7.

23. Berlinger NT. Robotic surgery: squeezing into tight places. N Engl J Med 2006;354:2099-101. 